\title{
DeEp DIVING UNDERWATER WORKS IN POLAND
}

\author{
Stanisław Skrzyński \\ Faculty of Mechanical and Electrical Faculty, Polish Naval Academy in Gdynia, Poland
}

\section{ABSTRACT}

In the article the author describes the Polish specificity of deep dives used in underwater deep-sea works. The article briefly discusses the methods of deep diving used in the world to proceed to underwater works in the Polish offshore zone of 50-90m depth (according to the Act; deep water works are works below a depth of $50 \mathrm{~m}$ ). When discussing these methods, the author describes the technical-organisational and formal conditions and the type of conducted works. It then presents the methodology for evaluating the effectiveness of the main element of deep-sea works, i.e. diving. It provides information on deepsea underwater works on the Baltic Sea carried out by the Department of Underwater Works Technology of the Naval Academy in cooperation with the Polish Navy until 2001 and civil companies to date. On the basis of his own data from underwater deep-sea works, the author presents the methodology of evaluation of their effectiveness from the point of view of deep dives. In his conclusions, he puts forward recommendations for improving the efficiency of such works. Keywords: deep underwater work, deep diving,professional diving, methods of diving, data deep diving, diving bell, efficiency of diving, diving mixtures, diver's decompression, decompression table.

\section{ARTICLE INFO}

PolHypRes 2019 Vol. 67 Issue 2 pp. 69 - 92

ISSN: 1734-7009 elSSN: 2084-0535

DOI: 10.2478/phr-2019-0007

\section{Review article}

Pages: 24, figures: 5 , tables: 6

page www of the periodical: www.phr.net.pl

Submission date: 12.01.2019 r.

Acceptance for print: $25.01 .2019 \mathrm{r}$.

Publisher

Polish Hyperbaric Medicine and Technology Society 


\section{INTRODUCTION}

We can distinguish three main fields of diving in the underwater activities of humans in the modern world. These are commercial diving, diving for military and special purposes diving, and recreational diving. They differ in their purpose, medical and technical protection and the degree of formalisation.

The Polish Navy has been preparing personnel for the introduction of deep diving since the 1960s. Until 1974, these personnel performed these dives in the USSR centres and ships of the USSR as part of their training. A rescue ship PIAST with had a deep diving system with a diving bell equipped was introduced in 1974 into the Polish Navy. Underwater deep-sea works carried out for PPiWRNiG Petrobaltic (LOTOS Petrobaltic since 2010) have been carried out on a large scale in our country by the Navy since 1982.

The level of safety and effectiveness of the implementation of these works has changed with the progress of science, which has resulted in the upgrade of technical facilities and the development of diving personnel. This progress was reflected in the diving technologies developed for the company and the Navy by the Department of Underwater Work Technology of the Naval Academy.

Until 2002, these works had been performed only by the Navy in our country, but in 2003, civil diving teams, formed mainly of reservists from diving units of the Armed Forces, appeared on the market of underwater services.

Since 2003, the implementation of deep-sea works has been imposed mostly by the Act on Underwater Work [9] and related normative documents, which formalized these works in the civil market. The "Regulation of the Minister of Health of 17 September 2007 on health conditions in underwater works" introduced pursuant to Article 11, paragraph 6 of the Act on underwater works [11] had a particular impact on the performance of these works. The Regulation directed the execution of underwater deep-sea works by imposing decompression tables, and also linked it with a specific diving techniques and medical protection, thus closing the chapter on the application of Polish solutions of experience and methods of deep diving based on Polish intellectual and technical potential.

Adapting to heliox mixtures and using the advantages of the new decompression tables contained in the Regulation would require the reconstruction of several knots and retrofitting of the diving technique available in the country. Therefore, diving technologies were adapted to their use without major changes in the diving technique used by civilian divers.

The decompression tables (French COMEX 1992) introduced as obligatory in this regulation for commercial deep diving corresponded to the technique and diving base $^{2}$ of France. This excluded the possibility of using other decompression tables appropriate to the technique. The regulation in its requirements also limited the group of physicians authorised to provide medical protection for this work.

Any underwater work carried out deeper than $50 \mathrm{~m}$ is a compromise between the task and the possibility of its execution. The potential possibilities for increasing diver safety during deep dives, whilst minimising the impact on the effectiveness of those deep dives, require precise preparation of work and organisation variants. The tables introduced by the Regulation provide many diving variants. Unfortunately, the national technical base of dividing does not provide these variants [14].

\section{INFORMATION ON COMMERCIAL DEEP} DIVING

According to the rules for worlwide commercial and military diving, it is assumed that deep dives are dives in the range of depths between $45-60 \mathrm{~m}$ and down to practically non-applicable depth of $180 \mathrm{~m}$. These boundaries are fluid as they result from the needs, scope of work, and the assessment of whether saturation diving will be more effective.

The approach to the deep diving problem, both in terms of the mixes used, diving depth zones, scuba, the formalisation of medical and technical protection, as well as the organisation and implementation of diving are country-specific. Deep diving in zones below 120-140 m are tolerated only in exceptional cases due to the high risk and very low efficiency.

Military deep diving is associated with high-risk tasks. Divers act alone or in pairs without direct protection. These are mainly mining or sabotage tasks. Deep-sea rescue work in the Navy is similar to commercial deep-sea rescue work. These dives use a broad protection technique, which require time, measured in days rather than hours, to develop.

The ineffectiveness of deep diving is expressed in the fact that with increasing depth the decompression time is close to the time of saturation diving decompression. Even with underwater works of several hours or more in the 50-90 m depth zone, saturation diving may be the most rational solution [6].

There are technical diving rules in deep recreational diving. These are dives of a short duration at depth with relatively short decompression in comparison to commercial diving. These dives do not use a wide range of technical and organisational protection, which is a fundamental divergence in dive organisation compared to commercial diving. During these dives, divers use independent scuba with "bottom" mix cylinders which are attached to the diver, and the so-called decompression cylinders which are sometimes staged at designated decompression stops. The standard configuration in technical diving is the unassisted open circuit (scuba) or closed circuit rebreather. Technical diving is performed by divers with a high level of professional qualifications with exceptional psychophysical predispositions [13]. The author considers these divers as the elite of the diving staff with the highest professional preparation.

\section{SHORT HISTORY OF WORLDWIDE DEEP DIVING}

The early use of deep diving is associated with marine rescue and recovery of sunken technical equipment after World War I. The best known use from this pioneering period is the underwater work carried out during the rescue of the crew of the American submarine USS Squalus from a depth of $74 \mathrm{~m}$ in August 1939 [1]. In this rescue operation, a heliox-type breathing mixture was used for the first time in operational diving. The economic and political necessity to conquer the depths required the diver's intervention. At the beginning of its path, the 
depths were reached with heliox mixtures and in the 1940s, trimix and hydrox mixtures were used. Helium was, and still is, a very expensive market product, and diving.

In 1930, US Navy divers reached a depth of $100 \mathrm{~m}$ [3] using heliox mixtures. A Swedish engineer working in the Swedish Navy reached a depth of $160 \mathrm{~m}$ using hydrogen. However after his unfortunate accident in the 1940s, hydrox (hydrogen-oxygen) mixtures were abandoned [4]. The Soviet Union also achieved its underwater successes; using heliox they reached the depth of $100 \mathrm{~m}$ using the standard scuba a few years after the American team. Work on increasing the depth also continued in France and Great Britain, especially after World War II with the record-breaking dive of British diver to a depth of 184 metres in 1958.

In 1962, the Helvetian Keller dived to a depth of $300 \mathrm{~m}$ using heliox mixtures, which to this day is a feat and one of the deepest dives using the so-called conventional diving, i.e. without the use of saturation diving technology.

Polish deep diving began in the 1960s and followed a similar path to its worldwide development. The maximum depths for the Polish economic zone in the Baltic Sea reach just over $110 \mathrm{~m}$. These diving activities began in the Navy and were dictated by the need to secure the rescue of submarines. In the eighties, these dives were necessary to secure the activities of the Polish offshore industry.

\section{DEEP DIVING CHARACTERISTIC}

Deep diving is consider the most difficult from the point of view of its organisation and underwater physiology due to:

- lack of full research recognition of decompression processes, which is associated with limited time at depth. There are no decompression tables for divers staying at depths for more than 1.5-2 hours in depth zones exeding $120-140 \mathrm{~m}$,

- $\quad$ high qualifications and experience requirements for divers and diving personnel,

- difficulties resulting from a high decompression risk and lack of clear procedures during decompression emergency situations, limited decompression procedures for short diving times at depth and long tiring decompression, and limited choice of decompression for medium and heavy duty jobs [12],

- very low efficiency as the duration of the diver's stay varies from a few to several percent of the total diving cycle. Therefore, these dives are used relatively rarely in global commercial diving, usually for low intensity work or intervention work. These dives are also used as safety and rescue diving in saturation diving. For example, tables used in our country (COMEX) for the duration of a diver's stay of 1 hour $44 \mathrm{~min}$ at a depth of $116 \mathrm{~m}$ require decompression lasting 25 hours $46 \mathrm{~min}$. [11],

- ambiguous choice of trimix or heliox mixtures for decompression process as a rule requiring one or more decompression mixtures and oxygen,

- shortening the decompression time in technical diving through the use of mixtures with oxygen at a physiologically acceptable high partial pressure
[10]. Due to the diver's relatively long time at the depth and performing work with different loads in commercial diving, the partial pressure of oxygen in both, operating mixtures and decompression mixtures is relatively lower. [5]. This results in long periods of decompression and its precise procedures. When selecting the decompression profile, we must take into account the permissible diving cycle time including oxygen toxicity. These restrictions reflect the operating and decompression mixtures prepared for specific narrow depth zones. For the $50-120 \mathrm{~m}$ depth zone, a minimum of 4 operating mixtures are required, which correspond to the appropriate work depths. [12] For example, a 2-hour stay at a depth of $180 \mathrm{~m}$ requires 48 hours of decompression using 4 decompression mixtures and oxygen [8],

- the restriction related to thermal protection of divers, which affect the limitations of time spent at depths associated with limiting the partial pressures of oxygen and inert gas. Increased thermal protection in deep diving results from a long stay of a diver in the pelagic zone and the cooling effect of helium. Although material engineering and technical progress are trying to solve this problem, the risk is real if decompression occurs in water. It should be noted that the cold is a very real threat to the proper decompression of the diver,

- times at depth, that are limited by tables, affect safety and emergency operations. The organization and technique of deep diving must be improved, and the diving system must ensure comfort during decompression, the process of treatment of decompression incidents and the provision of qualified medical assistance to the diver,

- $\quad$ specific therapeutic procedures. For example, if a diver has a rapid ascent to the surface, if the depth or time of stay provided in the tables is exceeded. This is a problem of decompression emergency tables and maintaining additional technique and appropriate stocks of medicinal mixtures. In the case of extreme emergency situations in deep diving it is necessary to use saturation diving technology.

For the above reasons, deep diving must be organised perfectly and the diving procedures must be described in great detail. At great depths, exceeding the time by a minute results in prolongation of decompression by a few hours.

\section{DEEP DIVING METHODS TAKING INTO ACCOUNT NATIONAL CONDITIONS}

The following methods are currently used worldwide in deep diving using breathing mixtures and oxygen decompression. All methods for commercial purposes are aimed at the shortest possible stay of divers in the pelagic zone during decompression.

The following diving methods can be used for deep-sea underwater activities:

- diving in unassisted scuba with open, semiclosed and closed circuit, 
- diving with surface-supplied equipment (using a drop rope or lowering the diver on a platform),

- $\quad$ diving with a wet diving bell,

- diving with an open diving bell (diving with an open hatch and with gas space inside the diving bell at a certain level), and

- diving with the use of a closed diving bell (the bell is immersed with a closed hatch).

Current formal documents in our country concerning commercial underwater deep-sea works allow to use only those methods that obligatorily use the diving bell. It is a requirement that ensures the safety and comfort of the diver, but it is very "annoying" for the clients of deepsea works due to the required outlays and wide technical protection.

\section{DIVING IN UNASSISTED SCUBA WITH OPEN, SEMI-CLOSED AND CLOSED CIRCUIT}

This is the "youngest" deep diving method. It has been developing since the last decade of the last century in our country. It derives from military diving. This method imposed a new specificity of training and adjustment of organisational requirements to the implemented diving technique and technology based on unassisted diving with unassisted scuba. This method selected the best divers and gave the opportunity to dive at great depths without requiring the entire protective kit imposed by professional diving regulations.

Technical diving was developed under recreational diving activities and is generally formalized depending on the diving organisation in which it developed [10]. The penetration of the "Lisutania" wreck located at $100 \mathrm{~m}$ in the USA was a shock to professional companies and the OSHA diving supervisory institution (The Occupational Safety and Health Administration). Those types of diving where against all rules and requirements of commercial diving. Contemporary groups of wreck surveyors penetrate wrecks looking for treasures, money, fame, serving the families of disaster victims or simply filming. Such an example can be the "Estonia" wreck, penetrated by groups of technical divers. Many specialists of technical diving consider these dives to be future-oriented and should not be underestimated [4].

The availability of this type of technology may encourage, for example, terrorist organisations to train themselves in this field. The secrecy of a technical diving diver's activity in deep waters is guaranteed, while costs and technical requirements are minimal.. Utilising a yacht or a fast boat for surface cover, the elite of technical divers can easily reach a depth of $120-150 \mathrm{~m}$ (the record in this type of diving is over $300 \mathrm{~m}$, including over 14 hours in water) and safely return to the surface. The introduction of a new generation of unassisted scubas with a closed circuit, electronically controlled with very long operation time (6-9 hours) creates a potentially wide range of possibilities for deep diving.

The investment and commissioning time of a diving system with unassisted scuba is incomparably small compared to a formalised and expensive commercial deep diving system. Technical diving has a very limited application due to:

- the working time of a diver in this method being very short, and the repetitiveness of the diver's work being very limited,

- increasing the degree of diving risk, usually without the possibility of providing qualified assistance in the event of specific diving sicknesses,

- the diver must very accurately copy the dive plan assumed in the computer, with no possibility of time correction due to the limited amount of mixtures in the cylinders, and

- $\quad$ a diver loaded with scuba, several cylinders and equipment allowing for a long stay at the pelagic zone.

A diver performing a parallel task performs the role of a diving manager. As a rule, technical diving takes place in a team with mutual safeguard [5]. The team is communicatively "cut off", although not always, with a protective base on the surface. This is unacceptable from the point of view of commercial and military diving. The accident rate in deep technical diving is 5 times higher than in commercial diving [17].

This method is not currently included in normal commercial diving regulations. Though it enters commercial diving territory through the "backdoor" due to its basic advantage; low cost and short mobilization time. This method was also used for commercial diving on the Baltic Sea. Spectacular examples include underwater works at a maximum depth of up to $80 \mathrm{~m}$ when laying a pipeline (in 2003) using a closed-circuit rebreathers, and in 2009, during the recognition of the Graf Zeppelin wreck at a depth zone of $60-86 \mathrm{~m}$. Currently, recreational diving expeditions to this wreck take place on a daily basis. I will also mention the tragic history of beating the Polish depth record of over $200 \mathrm{~m}$. that costed the lives of 3 divers [13].

\section{DIVING WITH TETHERING EQUIPMENT (USING DROP ROPE OR LOWERING PLATFORM)}

The working principle is almost identical to that of a lightweight cable equipment with air consumption. The range of used depths of $50-70 \mathrm{~m}$ is dictated by the limited time the diver stays at the pelagic zone (formal documents specify a maximum of three hours including decompression). This method requires a limited base on the surface (Fig. 1). Minimum diving team: 5-7 persons. 


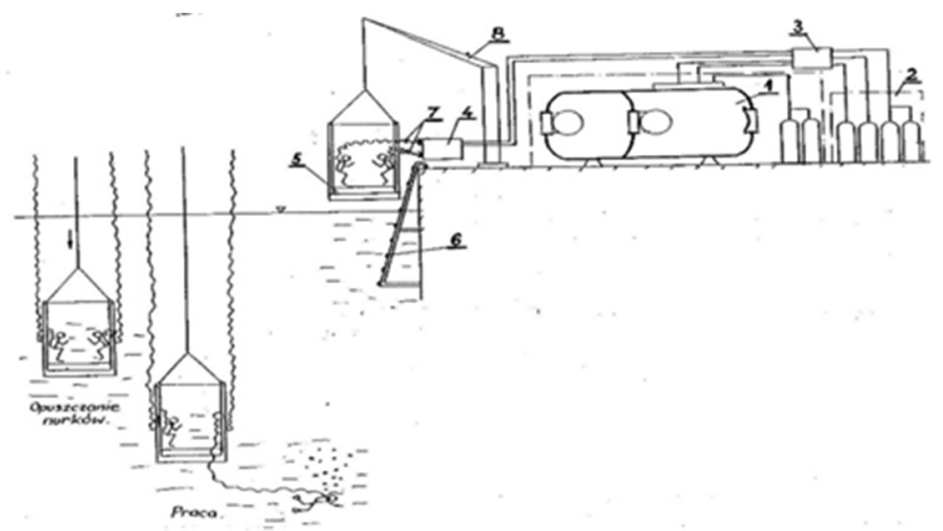

Fig. 1 The principle of deep diving from a landing or a diving platform. 1- two-compartment decompression chamber, 2- breathing gas stores, oxygen, mixtures and air, 3-power board, 4- dive board, 5-landing or diving platform, 6- diving boarding ladder, 7- diving cable and hose harness,8- lifting and lowering device.

Breathing equipment, similarly to traditional scuba diving, is rigged with two breathing gas supply systems from a single source and an emergency reserve (bailout). There are also semi-closed circuit umbilical supplied devices in the economical version. These devices, despite undoubtedly very economical breathing mixture consumption, have inconveniences expressed in increased breathing resistance and inability to precisely determine decompression in medium duty underwater works.

The time to perform a task at a depth in opencircuit gear is limited and is also dependent on the exertion of the diver, ranging from 10 to 30 minutes. Decompression at the pelagic zone uses mixtures with high relative partial pressure of oxygen. There are also tables that use surface decompression at the $50-90 \mathrm{~m}$ depth zone. The biggest advantage of this method is the possibility to perform underwater work from a temporary base [12].

\section{DIVING WITH A WET DIVING BELL}

Diving from a wet diving bell is the cheapest deep diving system to utilising a bell. The wet bell is a bowl supplied with breathing gases, communication and lighting from the surface, and is equipped with breathing equipment for oxygen decompression. The bell can be equipped with gas for decompression. This method allows control of the process of immersion and a controlled decompression in water. Although decompression takes place at the pelagic zone, the wet bell makes it possible to supply oxygen in its final phase. Though the divers stay at the pelagic zone for the entire diving cycle, the stay should not exceed 3 hours with unheated diving suits. The use of a wet bell is recommended for interventional diving up to a maximum depth of $70-80 \mathrm{~m}$ with a maximum stay of between 20 to 30 minutes [2].

The undeniable advantage of the wet diving bell is that it is easy to install on each unit and it can be used with all types of diving breathing equipment. The time needed to get the wet bell ready for operation is also considerably shorter than that needed for a closed diving bell. The open-circuit umbilicalled breathing apparatus is essential in commercial diving. While diving with a wet bell we can also use unassisted equipment, but such a configuration in commercial deep diving in our country is not considered acceptable according to the regulations.

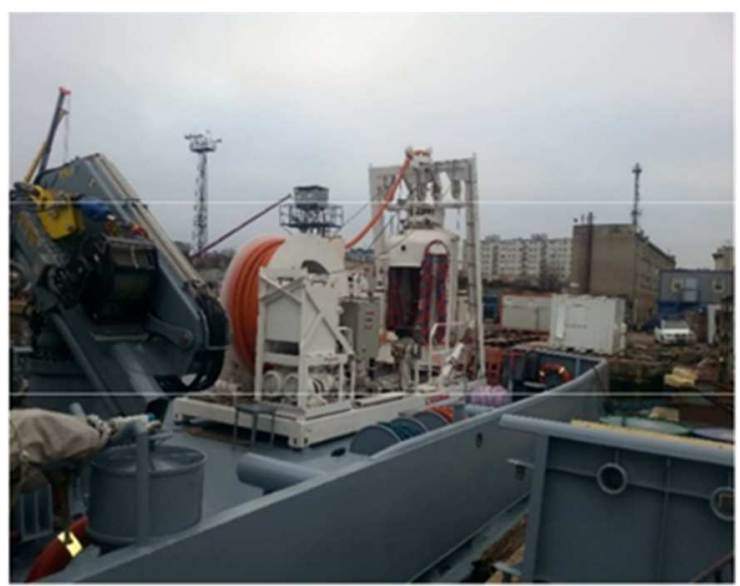

Fig. 2 Wet bell installed on the stern of the R14 ship. 
Restrictions on the use of the wet bell [15] introduce a maximum operating depth of $75 \mathrm{~m}$ with a 30min stay at that depth. The Polish Navy has the wet bell mounted on R14 rescue ships; the technology of its deep diving use remains open. Current formal documents of underwater works in our country concerning deep diving do not specify what type of diving bell must be used in deep water works. Therefore, this method is not prohibited in our country. The use of the wet bell for deep-sea works in the Baltic Sea conditions on most days of the year is limited by hydrometeorological conditions (water temperature, waves and water currents).

\section{DIVING WITH THE USE OF AN OPEN DIVING BELL}

Open diving bell (TUP, bounce diving) is a method used in underwater work in Poland. We have four diving systems in the country for the implementation of this method, including one system for saturation diving. This method can be relatively rationally used at the 50$100 \mathrm{~m}$ depth zone with dive times of up to 1.5 hours (the current tables in our country provide a maximum duration of stay up to 2 hours, including a 0.5 hours safety reserve). Divers make their first decompression stops in the atmosphere of the diving bell without the impact of the water environment. After the transfer under pressure at a selected decompression stop, divers go to a hyperbaric chamber where they continue decompression. In the final stage of decompression (from the $12 \mathrm{~m}$ stops) divers breathe pure oxygen requiring the use of a face mask (BIBS of the internal breathing system of the chamber). Oxygen decompression lasts several hours, which interferes with the comfort of staying in the chamber due to the necessity of breathing from masks. For example, a diving stay at the depth of $85 \mathrm{~m}$ lasting1 hour 25 minutes requires decompression of 13 hours 26 minutes, including oxygen decompression lasting 4.5 hours at decompression stops $12 \mathrm{~m}, 9 \mathrm{~m}, 6 \mathrm{~m}$ and $3 \mathrm{~m}$ during which divers breathe in cycles of 25 minutes and 5 min breaks during which they take off their masks.

Both open and closed bell requires a fully equipped diving scuba to provide conditions for deep diving. The team should comprise a minimum of 16-18 people, including 3 pairs of divers. The bell at the workplace allows the performance of the toughest work, because it provides a safe haven for a tired diver immediately after work. The disadvantage of this method is that a diving umbilical (the hose and cable bundle) is usually connected to the bell. Its standard length is $30 \mathrm{~m}$ (longer is possible for special procedures), which is conditioned by safety (limit the depth or ejection of diver towards the surface).

The organisation of diving with a bell, adopted from the beginning of the deep diving history specifies a pair of divers working underwater. A pair working at the pelagic zone is the best way to perform work as well as to safeguard each other. In recent years, diving with an open bell, due to the intervention of the administration, the pair is divided into tasks of a working diver and the bell operator. The bellman is equiped to go out into the pelagic zone because as the working diver stays at the depths, the bellman is in the bell. The bellman is without a helmet and equipment that could be restricting movement inside the bell. The bell is at the lesser depth than the working diver. The bellman acts as a safety diver, which in emergency situations secures the evacuation of the working diver to the bell. The bellman performs activities supporting the working diver from the bell, etc. In the case of a pair of divers, there is no problem with their entering the bell. Flooding the bell (only in bells prepared for this purpose) may facilitate the entry of the diver into the bell not only in emergency situations.

The decompression in the bell takes place in favourable conditions, without unnecessary effort and under full control of the surface service. Working breathing gases are usually transmitted through an umbilical from the bell, which also supplies the bell with power, lighting, communications and television. Emergency breathing gas and an electricity supply is provided by cylinders and batteries installed on the bell.

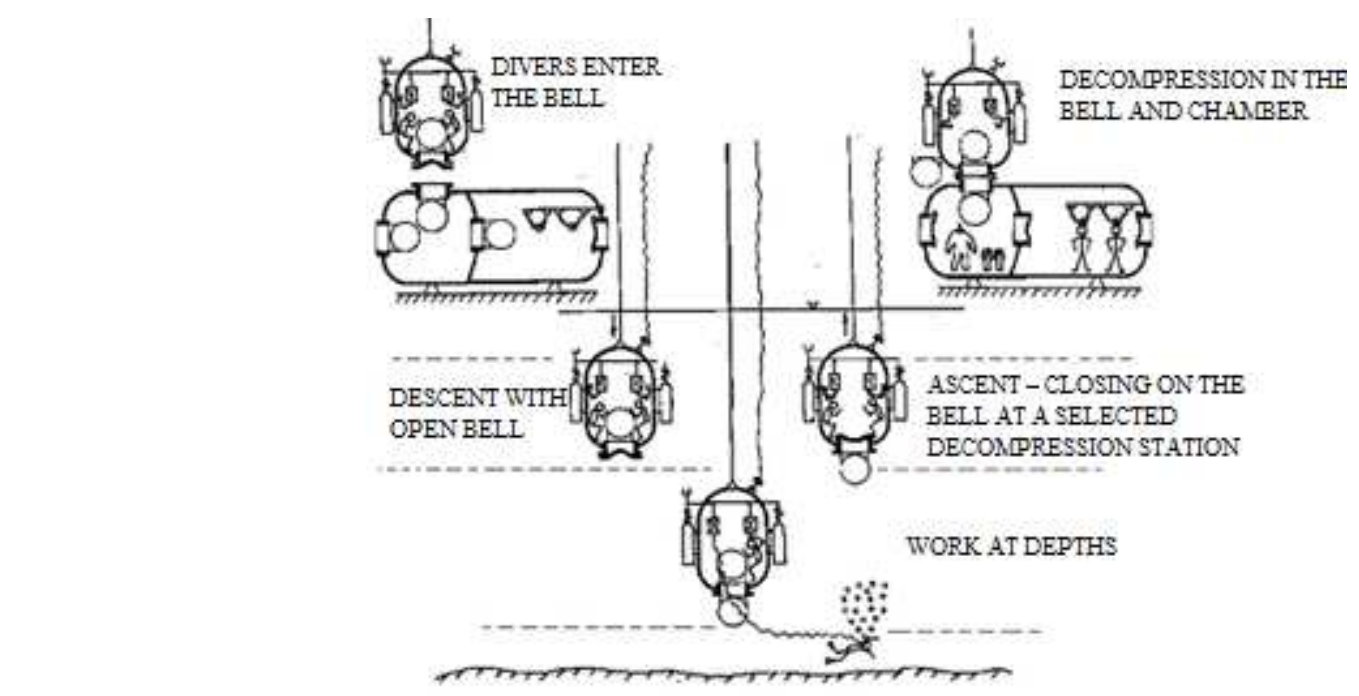

Fig. 3 Principle of operation of open bells. 
In phase I of the dive - immersion, the bell hatch is open and the descent speed depends on the possibility of equalising the pressure of divers and maintaining the"air safety cushion" in the bell. Phase II - stay at the bottom does not require any operation related to the bell. In phase III, decompression is carried out with the hatch of the bell open up to the decompression stop, at which point it is possible to transfer divers to the chamber. At this stop, the hatch is closed and the bell is raised quickly while observing the pressure in the bell (not allowing its change). The diving bell is a complicated structure and is built under the supervision of classification societies. It has a specific autonomy providing the time to act in an emergency situation.

The principle of operation of the open bell is shown in Figure 3. The disadvantage of this method is that the effective working time of a diver is reduced by the immersion time, which is included in the time of stay at the depth. It is important in the case of deep diving, because this time is extended with the depth of diving. The use of the bell determines that the passive or active thermal protection of the diver must be matched to the time the divers will stay at the pelagic zone.

In 2004 and 2005 an usage of open bell with no option to transfer divers under pressure (TUP) to the decompression chamber started. This method was applied using the diving system during the construction of the platform at the $52-56 \mathrm{~m}$ depth zone, using the MOBNUR diving system. This forces the whole decompression to take place in the bell or to use surface decompression for deep diving. The official tables of the Regulation of the Minister of Health of17 September 2007 do not include tables of surface decompression for deep diving.

This diving method shortens the working time of a diver underwater, because surface decompression is provided for short periods at depth and is provided for medium duty work.

\section{DIVING WITH A CLOSED BELL}

As a rule, this diving method uses the system for saturation diving. Diving, unlike saturation diving, is called bounce diving2.

diving method shortens the working time of a diver underwater, because surface decompression is provided for short periods at depth and is provided for medium duty work.

This method is the most effective of the deep diving methods used in the entire depth range, i.e. from50 to $180 \mathrm{~m}$. The main goal of this diving method is to shorten the descent to a minimum, i.e. the time spent under maximum depth pressure. For this purpose, the diving bell has two hatches, the lower one for the possibility of lowering the diver to the depth under atmospheric pressure and the upper one for the possibility of underpressure transfer of divers to the chamber. The diver reaches the depth in atmospheric pressure conditions, quickly equalises the pressure to the ambient pressure at the depth filling the bell with the working mixture. This makes it possible to shorten the time of reaching the working depth by as big a margin as possible. The speed of raising the pressure in the bell reaches an average of 30 $\mathrm{m} / \mathrm{min}$ and more, and the speed of descent slightly affects the cycle of diving. For example, the time of descent of the open bell to a depth of $100 \mathrm{~m}$ ranges from 8 to $12 \mathrm{~min}$ and would be included to the time of the diver's stay at the depth (such are the rules of selection of decompression in all tables known to me, except for Russian tables). When using a closed bell, the lifting time is also reduced to a few minutes. This is the method with the lowest risk in situations where the tabular stay times are exceeded, because the emergency state of this method is saturation diving.

The number of diving hours depends on the number of diving pairs that can "pass through" the hyperbaric compartments of the diving system. The hatch of the bell closes at the decompression stop, during which it is possible to quickly ascend the bell and transfer divers to the chamber. After the TUP operation, decompression takes place as in the case of an open bell. For example, when we have three hyperbaric chambers or a multicompartment chamber, each compartment is designed for the next pair of divers. One of the compartments of the chamber is kept on standby for possible recompression of therapeutic divers who have undergone decompression. The work of divers is performed without interruption during the day, using the so-called stream method. The principle of working with a closed bell is shown in Figure 4.

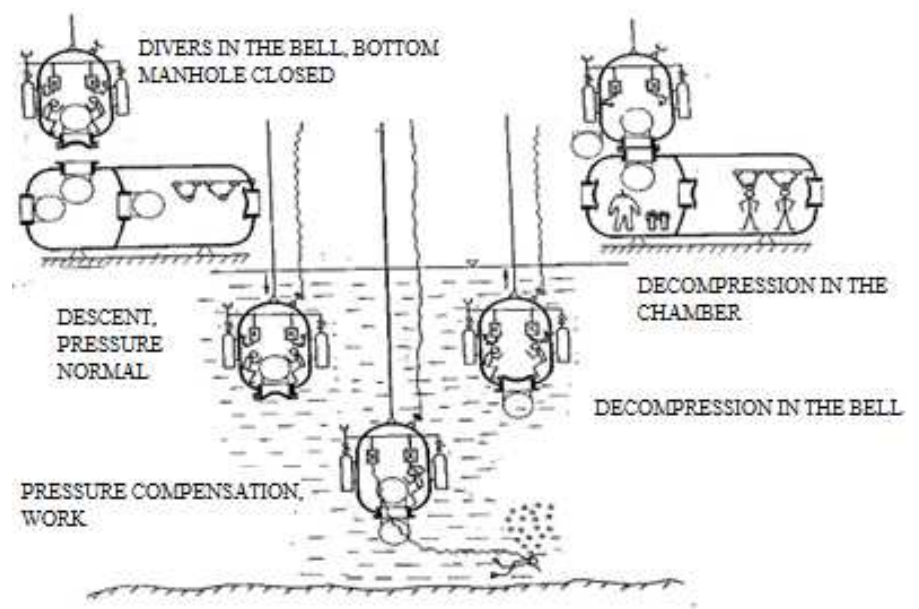

Fig. 4 The principle of diving with a closed bell (bounce). 
The time required to achieve readiness for the deployment of the saturation diving system and for deep diving is counted in days. Deep and saturation diving systems require vessels of medium displacement and preferably with a dynamic positioning system.

\section{DIVING PERFORMANCE WITH OPEN BELL}

\section{INDICATORS}

One of the basic indicators, in addition to safety, is efficiency when developing the technology of every method of diving, not only deep diving. Safety criteria are included and enforced in the legislation, recommendations and the so-called "good diving practice" and concern the organisation and technology as well as diving medicine.

On the other hand, effectiveness can be assessed in many aspects, e.g. financial outlays, time of work, choice of diving technique, diving crew and qualifications, consumption of breathing gases and consumables, organisational and financial consequences depending on the depth and amount of decompression, and characteristics of the diving technique, etc.

The author have been using the following evaluation of effectiveness for years, which indirectly includes the abovementioned problems. Taking the problem of effectiveness as a whole, a very complicated multi-layered system is created, which is assigned only to a specific diving system and its environment. The measurement of effectiveness for the comparison of diving technology, diving systems and underwater works should be carried out in the same conditions.

\begin{tabular}{|c|c|c|}
\hline No. & Bell diving parameters for the depth of 72 metres & Discriminants and units \\
\hline 1 & Ascent rate, real/allowable acc. to decompression table & {$[9 \mathrm{~m} / \mathrm{min}] /[30 \mathrm{~m} / \mathrm{min}]$} \\
\hline 2 & Time of bell descent to a depth of $72 \mathrm{~m}$ & $9 \min$ \\
\hline 3 & Time of diver's reaching of the place of work & $4 \mathrm{~min}$ \\
\hline 4 & Working depth of a diver* & $82 \mathrm{~m}$ \\
\hline 5 & Time of diver's return to the bell & $5 \mathrm{~min}$ \\
\hline 6 & Time of diver's stay at depth & $57 \mathrm{~min}$ \\
\hline 7 & Decompression time & $9 \mathrm{~h} 01 \mathrm{~min}$ (541min) \\
\hline 8 & Diving cycle time & 9h 58min (598min) \\
\hline 9 & Time spent in water depths (from ascent to operation implementation) & $2 \mathrm{~h} 41 \mathrm{~min}(161 \mathrm{~min})$ \\
\hline 10 & $\begin{array}{l}\text { Diving effectiveness coefficient } \mathrm{E}_{\mathrm{d}} \text { as a ratio of diver's stay time at depths } \\
\text { and the diving cycle time }\end{array}$ & $9.5 \%$ \\
\hline 11 & $\begin{array}{l}\text { Effectiveness coefficient } E_{n} \text { of diver's work as a ratio of diver's work time } \\
\text { at depths and the diving cycle time }\end{array}$ & $6.5 \%$ \\
\hline 12 & Ratio of diver's work time and depth $\mathrm{E}_{\mathrm{g}}$ & $65 \%$ \\
\hline
\end{tabular}

* The working depth of a diver is greater than the depth of a diving bell.

The author have chosen diving aspects to evaluate the effectiveness criterion. The assessment of diving effectiveness is based on the comparison of three indicators for given depths and variants of the use of decompression tables and the efficiency of a diver's work. The first Ed indicator concerns the effectiveness of applied decompression tables, calculated as the time of a diver's stay at a given depth to the duration of a diving cycle. The second parameter concerning the organisation of diving is the ratio of the actual time of a diver's work at the depth to the time of the diving cycle. The first Ed indicator is the starting point for the development of diving technology(Table 3). The second En $t$ index is a parameter that indicates the level of organisation of underwater work and is based on practice (Table 4). If these indicators are similar, it indicates effective underwater work, which is equivalent to efficient organisation of underwater work. The third one is the Eg indicator of the use of working time determined by the ratio of the working time of a diver to the time of the diver's stay at the depth (Table 5).

of course, other performance indicators are also taken into account and calculated, and only selected indicators are used for discussions with an underwater contractor. For example, when working in a 50-80m depth zone, we use only two working and decompression mixtures. We do not use the optimal mixture for a given depth, because we do not have a sufficient number of gas stores (cylinder bundles) and it is not optimal from the point of view of the outlay and organisation of underwater works.

The difference in the depth of the bell's descent and the depth of the diver's work also affects the effectiveness of the action. The diver's working depth is always greater than the depth of the bell. There are occasional cases where a diver performs partial tasks above the level of the diving bell. Descent of the bell, especially when the diver is working on the structures of wellhead station installations, requires that the bell and its stabilising ballasts are above these structures. This makes it easier for the diver to reach the place of work and return to the bell and avoid catching the bell on the structures in case of unforeseen shifting of the vessel from which the bell is lowered. 


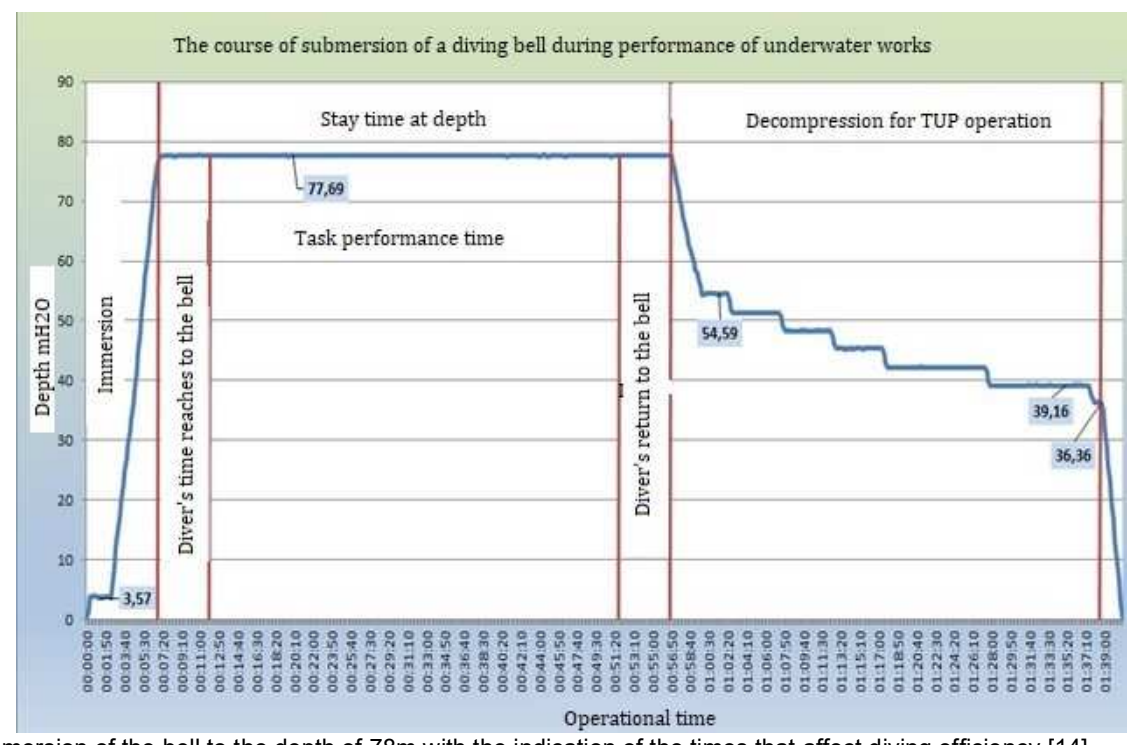

Fig. 5 The course of a real submersion of the bell to the depth of $78 \mathrm{~m}$ with the indication of the times that affect diving efficiency [14].

\section{DATA ON UNDERWATER WORKS ON THE POLISH SHELF}

Table 2 below presents the list of underwater works prepared and carried out by and in cooperation with the Department of Underwater Works Technology of the Polish Naval Academy for the needs of the Polish crude oil extraction industry since 1994. The applied technologies and procedures of deep diving after 1993 were developed in the Department in cooperation with the Chair of Maritime Medicine of the Military Medical Academy. Four decompression tables were used in commercial dives during the execution of underwater deep-sea works in Poland.

- US Navy tables using heliox until 1987 were adapted for semi-closed circuit apparatus FGGIII.

- $\quad$ Trimix tables were adapted from French DORIS tables for the FGG-III and for the open circuit apparatuses until 1995.

- Polish trimix tables for open circuit apparatus that were developed in cooperation with the Chair of Maritime Medicine of the Military Medical Academy were used till 2007.

- The forth type of tables, that are used obligatory in commercial diving since 2008 in our country, are heliox tables specified in the Regulation of the Minister of Health of 17 September 2007 on health conditions of performing underwater works [11].

With regard to the deep diving zone 50-120 defined in the said Regulation contains three types of tables depending on the diving technique used and the composition of the working and decompression mixture and oxygen in the last phase of decompression. Below author present a short summary of these tables.

I - heliox/oxygen/6m tables - designed for diving from a platform or with a dive rope and, of course, a diving bell. They cover a depth zone of 51-69m using heliox mixtures of $22-24 \% 02$ and $20-22 \% 02$. From a depth of $6 \mathrm{~m}$ the tables use oxygen in decompression. The intention of such a solution of oxygen decompression is its implementation in the water depth, which is acceptable in several countries. There are no references to this in Polish documents. For the purpose of decompression selection, stay times at depths are given every $10 \mathrm{~min}$. Maximum stay times for boundary depths of the zone are set at 90 and 60 minutes. 
List of underwater deep sea works since 1994 on the Polish shelf [14].

\begin{tabular}{|c|c|c|c|c|c|}
\hline No. & Year & No. of dives & $\begin{array}{l}\text { Depths } \\
{[\mathrm{m}]}\end{array}$ & Working mix & Underwater works base \\
\hline 1 & 1994 & 17 & $75-80$ & trimix & ORP Lech \\
\hline 2 & 1995 & 50 & $50-80$ & trimix & ORP Lech \\
\hline 3 & 1996 & 8 & $75-80$ & trimix & ORP Lech \\
\hline 4 & 1997 & 2 & $75-80$ & trimix & Af-2 Petrobaltic Platform \\
\hline 5 & 2001 & 42 & $75-80$ & trimix & Af-2 Petrobaltic Platform \\
\hline 6 & 2002 & 70 & $50-60$ & trimix & ORP Lech \\
\hline 7 & 2004 & 30 & $50-60$ & trimix & MOBNUR Platform \\
\hline 8 & 2005 & 24 & $50-60$ & trimix & MOBNUR Platform \\
\hline 9 & 2008 & 43 & $50-80$ & heliox & Af-2 ATHS Bazalt \\
\hline 10 & 2009 & 138 & $50-80$ & heliox & Af-2 ATHS Bazalt \\
\hline 11 & 2010 & 6 & $50-80$ & heliox & Af-2 ATHS Bazalt \\
\hline 12 & 2012 & 2 & $50-60$ & heliox & Af- 2 ATHS Bazalt \\
\hline 13 & 2013 & 84 & $50-61$ & heliox & Af-2 ATHS Bazalt \\
\hline 14 & 2014 & 41 & $50-80$ & heliox & Af-2 ATHS Bazalt \\
\hline 15 & 2015 & 19 & $50-81$ & heliox & Af-2 ATHS Bazalt \\
\hline 16 & 2016 & 57 & $50-84$ & heliox & Af- 2 ATHS Bazalt \\
\hline 17 & 2017 & 9 & $50-85$ & heliox & Af-2 ATHS Bazalt \\
\hline 18 & 2018 & 47 & $50-86$ & heliox & Af-2 ATHS Bazalt \\
\hline
\end{tabular}

II - heliox/oxygen/12m tables - for wet bell diving, decompression times are given every 10 minutes. Decompression is performed using air or heliox $20-22 \%$ 02 from a depth of $30 \mathrm{~m}$ and oxygen from a depth of $12 \mathrm{~m}$. Depending on the used mixture, they cover the following depth zones:

51-60m with the use of heliox mixes $20-22 \% 02$. Maximum stay times for boundary depths for the entire zone are set at $110 \mathrm{~min}$ and $60 \mathrm{~min}$.

51-69m with the use of heliox mixes 18-20\% 02. Maximum stay times for boundary depths for the entire zone are set at $100 \mathrm{~min}$ and $60 \mathrm{~min}$.

51-78m with the use of heliox mixes $17-18 \% 02$. At a depth of $6 \mathrm{~m}$ the tables use oxygen in decompression. From a depth of 24-36m the tables apply air and from 12 oxygen. Maximum stay times for boundary depths for the entire zone are set at $90 \mathrm{~min}$ and $50 \mathrm{~min}$.

III - heliox/bell tables - tables for closed and open bell diving, for the purpose of decompression selection stay times at depths are given every 15 minutes. Decompression is performed using working heliox and heliox $20-22 \% 02$ depending on the depth of the dive and oxygen from the depth of $12 \mathrm{~m}$. Minimum and maximum stay times are fixed for the entire depth zone of 50-120m and are indicated every $15 \mathrm{~min}$ up to $120 \mathrm{~min}$. Depending on the mix used, they cover the following depth zones:

51-69m with the use of heliox mixes $18-20 \% 02$.

$\mathbf{5 1 - 7 8 m}$ with the use of heliox mixes 16-18\% 02.

$\mathbf{5 1 - 8 7} \mathbf{m}$ with the use of heliox mixes $14-16 \% 02$. $\mathbf{5 7 - 9 9 m}$ with the use of heliox mixes 12-14\% 02 .

72-120m with the use of heliox mixes $10-12 \% 02$

Such an arrangement of decompression tables theoretically allows to conduct a dive at a depth of $75 \mathrm{~m}$, choosing a mixture from among 5 different options for different decompression times. In this case, we have five efficiency indicators.

The efficiency is also influenced by the structure of the tables. The decompression method for tables I and II is selected in intervals of 10 minutes. For example, when using tables III, the extension of the duration of stay by one minute, e.g. from 15 minutes to 16 minutes, means that we have to choose decompression for the time of stay of 30 minutes. In the case of Tables I and II, for decompression we should choose the method provided for the length of stay of 40 minutes and use air in its middle phase.

Decompression tables of heliox/bell in their structure take into account the time of bell handling, although the bell can be used for any table and mixture with the content in the Regulation of the Minister of Health of 17 September 2007. Other tables similar in their structure do not have such extensive possibilities of handling mixtures. In these tables we also select the mixture according to the depth but the maximum stay times do not exceed $60 \mathrm{~min}$.

Table 4 and 5 shows the effect of using particular types of decompression tables on the duration of the dive cycle. Differences in decompression time for specific methods of its implementation for the same initial parameters reach hours, which is visible in the dive 
efficiency indicators.

The length of decompression after 40 minutes long stay at depth for selected depths of the Polish shelf while using heliox mixtures in accordance with the decompression tables from the Regulation of the Minister of Health of 17 September 2007 on the health conditions of underwater work [11].

Decompression for the time of stay at a depth of $40 \mathrm{~min}$.

\begin{tabular}{|c|c|c|c|c|c|c|}
\hline No. & Depth & $\begin{array}{l}\text { Heliox mix } \\
\mathrm{O}_{2} \text { content }\end{array}$ & $\begin{array}{l}\text { Heliox/oxygen } / 12 \mathrm{~m} \\
\text { tables } \\
\text { Decompression time } \\
{[\mathrm{h}: \mathrm{min}]}\end{array}$ & $\begin{array}{l}E_{d} \text { indicator } \\
{[\%]}\end{array}$ & $\begin{array}{l}\text { Heliox/bell tables } \\
\text { Decompression } \\
\text { time } \\
\text { [h: min] }\end{array}$ & $\begin{array}{l}E_{\mathrm{d}} \text { indicator } \\
{[\%]}\end{array}$ \\
\hline 1 & \multirow{2}{*}{$60 \mathrm{~m}$} & $18-20 \%$ & $2: 19 *$ & 22.3 & $2: 45$ & 19.5 \\
\hline 2 & & $20-22 \%$ & $2: 11$ & 23.4 & $2: 26$ & 21.5 \\
\hline 3 & \multirow{4}{*}{$70 \mathrm{~m}$} & $10-12 \%$ & not applicable & - & $5: 33$ & 10.7 \\
\hline 4 & & $12-14 \%$ & not applicable & - & $5: 16$ & 11.2 \\
\hline 5 & & $14-16 \%$ & not applicable & - & $4: 54$ & 12.0 \\
\hline 6 & & $16-18 \%$ & $3: 14^{*}$ & 17.1 & $3: 59$ & 14.3 \\
\hline 7 & \multirow{3}{*}{$80 \mathrm{~m}$} & $10-12 \%$ & not applicable & - & $7: 04$ & 8.6 \\
\hline 8 & & $12-14 \%$ & not applicable & - & $6 ; 39$ & 9.1 \\
\hline 9 & & $14-16 \%$ & not applicable & - & 6:09 & 9.8 \\
\hline 10 & \multirow{2}{*}{$90 \mathrm{~m}$} & $10-12 \%$ & not applicable & - & $8 ; 49$ & 7.0 \\
\hline 11 & & $12-14 \%$ & not applicable & - & $7: 59$ & 7.7 \\
\hline
\end{tabular}

En indicators tables for deep dives tables used in Poland [14].

\begin{tabular}{|c|c|c|c|c|}
\hline \multirow{2}{*}{ Depth } & \multirow{2}{*}{ Tables/Mix } & \multicolumn{3}{|c|}{ Stay time / effectiveness $E_{n}$} \\
\hline & & $30 \mathrm{~min} /[\%]$ & $45 \mathrm{~min} /[\%]$ & $60 \mathrm{~min} /[\%]$ \\
\hline \multirow{4}{*}{$\begin{array}{l}\Xi \\
8 \\
\end{array}$} & Polish Navy/ trimix & $18.3 \%$ & $19.9 \%$ & $21.6 \%$ \\
\hline & US Navy/ heliox [1] & $25.6 \%$ & $24.7 \%$ & $35.9 \%$ \\
\hline & Polish trimix [12] & $17.8 \%$ & $19.8 \%$ & $21.6 \%$ \\
\hline & National -COMEX heliox [11] ${ }^{*}$ & $28.8 \%$ & $26.3 \%$ & $25.4 \%$ \\
\hline \multirow{4}{*}{$\begin{array}{l}\Xi \\
\stackrel{\Omega}{\rho}\end{array}$} & Polish Navy/ trimix & $15.3 \%$ & $16.9 \%$ & $17.8 \%$ \\
\hline & US Navy/ heliox & $20.7 \%$ & $23.4 \%$ & $31.3 \%$ \\
\hline & Polish / trimix & $14.7 \%$ & $16.4 \%$ & $17.5 \%$ \\
\hline & Krajowe- COMEX /heliox* & $23.9 \%$ & $18.4 \%$ & $17.3 \%$ \\
\hline \multirow{4}{*}{$\begin{array}{l}\Xi \\
\infty \\
\infty\end{array}$} & Polish Navy/ trimix & $11.8 \%$ & $12.4 \%$ & $13.5 \%$ \\
\hline & US Navy/ heliox & $18.4 \%$ & $21.0 \%$ & $28.0 \%$ \\
\hline & Polish trimix & $14.8 \%$ & $12.2 \%$ & $12.9 \%$ \\
\hline & National - COMEX heliox* & $12.8 \%$ & $12.7 \%$ & $11.6 \%$ \\
\hline \multirow{4}{*}{$\frac{\stackrel{*}{*}}{\stackrel{*}{\Xi}}$} & MW/ trimix & $9.8 \%$ & $10.3 \%$ & $11.4 \%$ \\
\hline & US Navy/ heliox & $16.7 \%$ & $17.9 \%$ & $25.4 \%$ \\
\hline & Polish trimix & $9.5 \%$ & $10.0 \%$ & $10.8 \%$ \\
\hline & National- COMEX heliox* & $9.9 \%$ & $9.3 \%$ & $9.1 \%$ \\
\hline
\end{tabular}

*Data for working heliox with oxygen content of $15 \% \pm 1 \%$.

${ }^{* *}$ Maximum depth for using heliox with oxygen content of $14-16 \%$.

Tables 3,4,5 and 6 show values in Eg Ed i En indices from selected underwater works from the years 2008-2013. Percentage values of indices are increasingly lower with increasing depth and time of a diver's stay at depth for obvious reasons of increase in decompression time and relation of operational activities of a diver to extended stay time. The decision to select a shorter decompression period brings visible effects already after several deep dives and so-called stream dives.

Moreover, shorter decompression means less expense, consumption of gas energy and shorter work of the diving team. This positive aspect will be disturbed if the diver's remuneration is dependent on the length of the dive cycle, where decompression is the most decisive factor. In this case, the tendency will be to lengthen it. In most dive companies, divers receive a lump sum remuneration for a contractual working day. 
En indicators table for deep dives decompression tables used in Poland [14].

\begin{tabular}{|c|c|c|c|c|}
\hline \multirow{2}{*}{ Depth } & \multirow{2}{*}{ Tables/Mix } & \multicolumn{3}{|c|}{ Stay time /effectiveness indicator $\mathrm{E}_{\mathrm{n}}$} \\
\hline & & $30 \mathrm{~min} /[\%]$ & $45 \mathrm{~min} /[\%]$ & $60 \mathrm{~min} /[\%]$ \\
\hline \multirow{4}{*}{$\begin{array}{l}\Xi \\
\Xi \\
ઠ\end{array}$} & Polish Navy/ trimix [17] & $15.5 \%$ & $16.6 \%$ & $17.8 \%$ \\
\hline & US Navy/ heliox [1] & $20.4 \%$ & $21.2 \%$ & $26.4 \%$ \\
\hline & Polish trimix [12] & $15.1 \%$ & $16.5 \%$ & $17.8 \%$ \\
\hline & National- COMEX heliox [11] ${ }^{*}$ & $22.4 \%$ & $20.8 \%$ & $20.3 \%$ \\
\hline \multirow{4}{*}{$\stackrel{\Xi}{\circledR}$} & Polish Navy/ trimix & $13.3 \%$ & $14.4 \%$ & $15.1 \%$ \\
\hline & US Navy/ heliox & $17.1 \%$ & $19.0 \%$ & $23.8 \%$ \\
\hline & Polish trimix & $12.8 \%$ & $14.1 \%$ & $14.9 \%$ \\
\hline & National -COMEX /heliox* & $19.3 \%$ & $15.5 \%$ & $14.8 \%$ \\
\hline \multirow{4}{*}{$\begin{array}{l}\Xi \\
\varnothing \\
\infty\end{array}$} & Polish Navy/ trimix & $10.6 \%$ & $11.0 \%$ & $11.9 \%$ \\
\hline & US Navy/ heliox & $15.5 \%$ & $17.4 \%$ & $21.9 \%$ \\
\hline & Polish trimix & $12.9 \%$ & $10.9 \%$ & $11.5 \%$ \\
\hline & National - COMEX heliox* & $11.3 \%$ & $11.3 \%$ & $10.4 \%$ \\
\hline \multirow{4}{*}{$\frac{\stackrel{*}{*}}{\stackrel{*}{\Xi}}$} & Polish Navy/ trimix & $8.9 \%$ & $9.3 \%$ & $10.2 \%$ \\
\hline & US Navy/ heliox & $14.3 \%$ & $16.0 \%$ & $20.3 \%$ \\
\hline & Polish trimix & $8.6 \%$ & $9.4 \%$ & $9.7 \%$ \\
\hline & National- COMEX heliox* & $9.0 \%$ & $8.5 \%$ & $8.4 \%$ \\
\hline
\end{tabular}

Eg indicators tables in relation to the exploitation of time of work [14].

\begin{tabular}{|c|c|c|c|}
\hline $\begin{array}{l}\text { Depth } \\
{[\mathrm{m}]}\end{array}$ & $\begin{array}{l}\text { toper for stay time of } 30 \mathrm{~min} \\
{[\mathrm{~min}]}\end{array}$ & $\begin{array}{l}t_{\text {oper for stay time of } 30 \mathrm{~min}} \\
\text { [min] }\end{array}$ & $\begin{array}{l}\text { Eg indicator } \\
{[\%]}\end{array}$ \\
\hline 60 & 14 & 16 & 53 \\
\hline 70 & 15 & 15 & 50 \\
\hline 80 & 16 & 14 & 47 \\
\hline \multirow[t]{2}{*}{90} & 17 & 13 & 43 \\
\hline & $\begin{array}{l}t_{\text {oper for stay time of } 45 \mathrm{~min}} \\
\text { [min] }\end{array}$ & $\begin{array}{l}t_{\text {oper for stay time of } 45 \mathrm{~min}} \\
{[\mathrm{~min}]}\end{array}$ & $\begin{array}{l}\text { Eg indicator } \\
{[\%]}\end{array}$ \\
\hline 60 & 14 & 31 & 62 \\
\hline 70 & 15 & 30 & 67 \\
\hline 80 & 16 & 29 & 71 \\
\hline \multirow[t]{2}{*}{90} & 17 & 28 & 76 \\
\hline & $\begin{array}{l}\text { toper for stay time of } 60 \mathrm{~min} \\
{[\mathrm{~min}]}\end{array}$ & $\begin{array}{l}\text { toper for stay time of } 60 \mathrm{~min} \\
{[\mathrm{~min}]}\end{array}$ & $\begin{array}{l}\text { Eg indicator } \\
{[\%]}\end{array}$ \\
\hline 60 & 14 & 46 & 77 \\
\hline 70 & 15 & 45 & 75 \\
\hline 80 & 16 & 44 & 73 \\
\hline 90 & 17 & 43 & 72 \\
\hline
\end{tabular}

The table records: toper time of diver's operation along with ascending and time of return to the diving bell, twork - time conducting an underwater task.

\section{CONCLUSIONS AND SUGGESTIONS}

- Deep dives in underwater works, despite their very low effectiveness, will continue to be applied, but only within depth zones where they can compete with saturation dives. The depth zones of the Polish oil and gas extraction shelf, predominantly with a depth of $50-90 \mathrm{~m}$, are the zones of such competition. The "pure" diving aspects of underwater deep-sea works are relegated to the background in the case of the specificity, scope and technology of underwater works which are imposed by the ordering party. The effectiveness of deep dives is "abandoned" in favour of a timely end result and business benefits.

- Deep dives for commercial purposes are maintained within a corset of formalisation which does not allow for a flexible approach to market needs, where efficiency is important with the principle of the optimal investment and maximum effect. Dives that comply with this principle are technical dives. They require the selection and preparation of diving technique and decompression for specific underwater tasks. I believe that this method of diving should be officially introduced into commercial diving in our country. It has been functioning in the world 
for many years next to the mainstream commercial works. For instance, the execution of underwater films, searches, intervention works. The introduction of this method to underwater works will influence the updating of formal documents and the development of deep diving.

- We use decompression tables from 1992 for our deep-water works, which means that the work on them began at the end of the 1970s. The theory of deep dive decompression has evolved towards more accurate modelling and selection for specific tasks. Our country should establish a centre of verification of current decompression models used for technical and military dives, as well as those serving the national economy.

- Increasing the effectiveness of deep dives should be considered in three problem categories: shortening the time it takes to reach a diver's workplace, organising the improvement of an underwater task and selecting the optimal decompression.

- The effectiveness of the currently used deep dives can be increased by:

$\checkmark$ not assigning the divers' activities to a particular type of a decompression table, but enabling their selection,

$\checkmark \quad$ approval of methods of diving without the use of a diving bell in deep underwater works, e.g. to a depth of $75 \mathrm{~m}$ or according to the "range" of a given diving technology. I believe that it is necessary to introduce "light" diving technologies for small-scale works (without the use of a diving bell),

$\checkmark$ improvement of the diving technique, e.g. introduction of a closed-type bell,

$\checkmark$ obligatory use of techniques supporting the performance of the diver's work, e.g. an ROV that accompanies the diver from the preparation of the work through the analysis of data from the diving survey (film from the workplace), thus leading the diver to the place of the underwater task and observe his/her operation.

- Underwater deep-sea works in our country are not a daily occurrence on the market of underwater services, but take place in the form of campaigns with relatively long intervals (sometimes reaching over a year). This fact does not have a positive impact on their development. Therefore, the providers of underwater deep-sea works direct their efforts to maintain the potential of their execution. Such works are also necessary for the defence of the country. In order to maintain the national technical and organizational potential for their implementation, cooperation between the civil and defence sectors is necessary.

\title{
REFERENCES
}

1. US Navy Diving Manual". Published by Direction of Comander of Navy. Revision 7, 2016;

2. NOAA Diving Manual" Diving for Science and Technology US Department of Commerse USA 2002;

3. Skrzyński S. - „Historical background of deep dives in Poland. Part I General characteristics of deep dives.” Polskie Towarzystwo Medycyny i Techniki Hiperbarycznej, czasopismo: Polish Hyperbaric Research 2006;

4. Nuno Gomez. Brief history of deep technical diving in the last 20 years. Artykuł 2009 www.mydivealbum.com;

5. Tom Mount "Technical diver" IANTD edition first 1998. ISNB 0-915539

Imber P. - „Commercial diving: 90m operational aspects” Divetech, Chemin des Vignasses rok 2003;

Consensus standard for commercial diving operations" Association of Diving; Contractors INC 6 - th edition 2011;

JP Imbert, D Paris, J Hugo "The Arterial Bubble Model for Decompression Tables Calculations. Debetach 2004;

Ustawa z dnia 17 października 2003 r. o wykonywaniu prac podwodnych;

10. T. Mount, B. Gikiam. ,Mixed gas diving” Watersport Publishing Inc. San Diego USA 1993 ISBNO - 922769-41-9;

11. Regulation of the Minister of Health of 17 September 2007 on health conditions for the performance of underwater works;

12. Targeted Project No. 11/BO Contract No. 148 308/C-T00/2001: "Deep Dives for Marine Rescue". Analysis of foreign deep diving systems in the context of national circumstances

13. Exchange of views on deep diving with foreign and domestic specialists;

14. Data from underwater deep-sea works on the Polish shelf:

15. Diving Recommended Practice Report No. 411 June 2008 The International Association of Oil \& Gas;

16. The professional diver's hand book John Bevan SUBMEX 2005;

17. Sygn. Mar. Woj. 860/81: Tabele dekompresji i rekompresji nurków. Dowództwo Marynarki Wojennej, Gdynia 1982 ;

18. Michael Menduno "Anatomy of a Commercial Mixed-Gas Dive" http://www.alertdiver.com 2012.

\author{
Stanisław Skrzyński \\ Akademia Marynarki Wojennej \\ im. Bohaterów Westerplatte $81-103$ Gdynia 3 \\ ul. Śmidowicza 69 \\ tel. : +58 6262746 \\ e-mail: skrzynski@interecho.com
}

\footnotetext{
${ }^{1}$ According to Art.2, point 1 of the regulation (9): 1) underwater work base; place of installation of equipment and technical devices that are crucial for enabling divers safe preparation and carrying out of underwater works, and also activities after work completion:

2 The word "bounce" is also used as a name for short diving.
} 